\title{
Partners' controlling behaviors and intimate partner sexual violence among married women in Uganda
}

\author{
Stephen Ojiambo Wandera ${ }^{1,2^{*}}$, Betty Kwagala ${ }^{1,2}$, Patricia Ndugga ${ }^{1,2}$ and Allen Kabagenyi ${ }^{1,2}$
}

\begin{abstract}
Background: Studies on the association between partners' controlling behaviors and intimate partner sexual violence (IPSV) in Uganda are limited. The aim of this paper was to investigate the association between IPSV and partners' controlling behaviors among married women in Uganda.

Methods: We used the 2011 Uganda Demographic and Health Survey (UDHS) data, and selected a weighted sample of 1,307 women who were in a union, out of those considered for the domestic violence module. We used chi-squared tests and multivariable logistic regressions to investigate the factors associated with IPSV, including partners' controlling behaviors.

Results: More than a quarter (27\%) of women who were in a union in Uganda reported IPSV. The odds of reporting IPSV were higher among women whose partners were jealous if they talked with other men ( $\mathrm{OR}=1.81 ; 95 \% \mathrm{Cl}: 1.22-2.68)$, if their partners accused them of unfaithfulness $(\mathrm{OR}=1.50 ; 95 \% \mathrm{Cl}: 1.03-2.19)$ and if their partners did not permit them to meet with female friends ( $O R=1.63 ; 95 \% \mathrm{Cl}: 1.11-2.39)$. The odds of IPSV were also higher among women whose partners tried to limit contact with their family $(\mathrm{OR}=1.73 ; 95 \% \mathrm{Cl}: 1.11-2.67)$ and often got drunk (OR=1.80; 95\% Cl: 1.15-2.81). Finally, women who were sometimes or often afraid of their partners (OR=1.78; $95 \% \mathrm{Cl}: 1.21-2.60$ and $\mathrm{OR}=1.56 ; 95 \%$ Cl: 1.04-2.40 respectively) were more likely to report IPSV.

Conclusion: In Uganda, women's socio-economic and demographic background and empowerment had no mitigating effect on IPSV in the face of their partners' dysfunctional behaviors. Interventions addressing IPSV should place more emphasis on reducing partners' controlling behaviors and the prevention of problem drinking.
\end{abstract}

Keywords: Intimate sexual partner violence, Empowerment, Alcohol, Controlling behaviors, Uganda

\section{Background}

Sexual and gender-based violence is a major social and public health problem $[1,2]$ with immediate and long-term negative consequences [3]. Sexual violence in particular leads to negative psychological, behavioral, physical, and reproductive health outcomes [1,4]. These include a heightened risk of HIV and sexually transmitted infections $[5,6]$, gynecological and sexual disorders, pregnancy complications, miscarriages and low birth weight [7].

\footnotetext{
* Correspondence: swandera@gmail.com

'Department of Population Studies, School of Statistics and Planning, College of Business and Management Sciences, Makerere University, Kampala, Uganda

${ }^{2}$ Centre for Population and Applied Statistics, Makerere University, Kampala, Uganda
}

\section{Biomed Central}

Worldwide, approximately $35 \%$ of women have experienced either physical or sexual violence, or both. Between 2006 and 2011, the percentage of Ugandan women who reported that they had ever experienced violence decreased from $39 \%$ to $28 \%$. In the same period, the percentage of women who reported that they had experienced sexual violence in the twelve months preceding the survey decreased from $25 \%$ to $16 \%$. The prevalence remains unacceptably high, however. In Uganda, $55 \%$ of ever married women identified intimate partners (husbands or male partners) as the perpetrators of sexual violence $[8,9]$.

Intimate partner sexual violence (IPSV) is among the most common forms of gender-based violence in Uganda. Among women who were in a union, $27 \%$ had ever experienced IPSV from their current partner and about 
one in five (21\%) had experienced sexual violence from an intimate partner in the 12 months prior to the survey [8].

IPSV is justified or tolerated in some cultures in South Africa [10] and Uganda [11]. This is because of associated beliefs that condone sexual violence within marriage and weak law enforcement $[12,13]$. In such contexts, women rarely report IPSV cases outside the family context. In Uganda, sexual violence ranked high among the types of violence where the majority of victims $(65 \%)$ never sought help or told anybody [8].

In some contexts, demographic and socio-economic factors account for variations in IPSV occurrence. Significant predictors of IPSV include the woman's age, age at first sex, type of marriage relationship, level of education, wealth status, and geographical region $[2,11,14]$. In rural Uganda, IPSV was associated with being young, an early age at first sex, consensual unions, and a low level of education [11]. In addition, poor wealth status significantly increases the likelihood of IPSV. The need for economic support often results in early (and possibly coerced) sex and marriage $[11,12,15]$. In Uganda, the likelihood of reporting IPSV was higher in the eastern and western regions than in the northern region [15].

Patriarchal notions of masculinity permeate IPSV. These notions reinforce men's control over women and their belief in unconditional sexual entitlement in marriage. In addition, IPSV is a method of punishment for noncompliance with partners' demands in a relationship. The occurrence of sexual violence was positively associated with women's attitudes justifying wife beating and women earning more than their partners. Women who had decision-making autonomy had a lower likelihood of experiencing physical and sexual violence $[12,16,17]$.

Socialization, particularly in family contexts in the formative years of life has a significant bearing on behavior during adulthood. In particular, witnessing parental violence during childhood is associated with re-victimization and an intergenerational cycle of violence for both girls and boys $[12,18]$. Intimate partner physical (battering) and sexual violence are closely related [19]. While several studies have established the relationship between witnessing physical intimate partner violence and experiencing physical violence $[12,18,20]$, its association with sexual violence in Uganda is yet to be established.

Male partners' controlling behavior in unions, their alcohol consumption and women's fear of their partners have been associated with intimate partner violence $[12,13,15,17]$. Factors associated with intimate partner physical violence (IPPV) among women who are in a union in Uganda include women's occupation; wealth status; parity; witnessing parental violence and whether women were afraid of their partners. In addition, partners' controlling behaviors - including accusing women of unfaithfulness, denying them permission to meet their female friends, insisting on knowing their whereabouts, and getting drunk sometimes or often - were associated with IPPV [20].

Studies investigating IPPV usually combine both physical and sexual violence $[6,14,21,22]$ yet contextual social perceptions of the two may differ [20]. On the other hand, studies that specifically address IPSV did not consider women's empowerment and male partners' controlling behaviors [23]. Therefore, this paper assessed the association between women's empowerment, partners' controlling behaviors, and intimate partner sexual violence among women who are in a union in Uganda.

\section{Methods}

\section{Data source}

We used the 2011 Uganda Demographic and Health Survey (UDHS) data, accessed with permission from the DHS Program website [24]. This was a cross-sectional nationally representative survey that used a stratified two-stage cluster sampling design [8] based on the sampling frame from the 2002 population and housing census [25]. A detailed description of the sampling procedure was reported in the 2011 UDHS report [8].

The sample for the domestic violence (DV) module was 2,056 ever-married women. From this sample, we extracted a weighted sample of 1,307 women who reported being in a union, for further analysis [8]. We used the domestic violence weighting variable (d005) included in the UDHS data and the Stata survey (svy) command to apply the weights during the analyses. Survey weighting is necessary to account for the complex survey design [26].

In this paper, women in a union included those who were married or cohabiting with their partners. The domestic violence module was based on a shortened and modified version of the Conflict Tactics Scale (CTS) [27]. The survey was carried out based on the World Health Organization's (WHO) ethical and safety recommendations for research on domestic violence [28].

\section{Measures of outcome variable}

In the DHS, intimate partner sexual violence (IPSV) was measured as having experienced any sexual violence from a current or former partner in the 12 months prior to the survey [29]. For IPSV, women in a union were asked the following questions: a) Have you ever been physically forced into unwanted sex by your husband/ partner? b) Have you ever been forced into other unwanted sexual acts by your husband/partner? c) Have you ever been physically forced to perform sexual acts when you did not want to? The binary responses from these three questions were merged into an aggregate measure of intimate partner sexual violence (variable d108 in DHS), which was coded as $0=$ no, and $1=$ yes. 


\section{Measures of explanatory variables}

We classified independent variables into three categories: first, women's empowerment indicators, namely participation in decision-making, attitudes justifying physical violence, and economic empowerment indicators. The second group of variables comprised husbands/partners' controlling behavior, women's fear of their partners, and their partners' alcohol consumption. The third category of explanatory variables included women's socio-demographic factors such as having witnessed parental violence themselves. This categorization was used in our earlier publication [20]. The term "partner" in this paper includes husbands as well as partners in cohabiting unions.

Five indicators in the DHS measured women's participation in household decision-making. Earlier publications have used these indicators [20,29]. In this paper, we used all five measures of decision-making autonomy regarding who usually makes decisions about: a) how women's earnings are used; b) women's healthcare; c) large household purchases; d) visits to family or relatives; and e) what to do with the money the partner earns. Responses to these questions were recoded into two categories $(1=$ woman decides alone/jointly with partner, $0=$ partner alone/others). The assumption was that women who made decisions either alone or jointly with their partners were more empowered than those in households where decisions were made by either their partners alone or other people [20,29].

Attitudes justifying physical violence were measured by questions concerning whether wife beating was justifiable if the wife: a) goes out without telling partner; b) neglects their children; c) argues with her partner and d) refuses to have sex with her partner. Responses to these variables were dichotomous $(1=$ "yes" or $0=$ "no"). Although, some studies have aggregated these measures [29,30], we preferred individual measures of empowerment [29]; our aim was to investigate the contribution of specific empowerment measures in influencing IPSV in the Ugandan context.

As described elsewhere [20], “women's economic empowerment included occupation and ownership of property (a house). Ownership of a house was recoded into two categories: woman alone/jointly with the partner as the empowered category and partner alone/others as the other. Ownership of a house is included because it is an important and contested asset for women in the Ugandan context" [20].

Partners' behavior and controlling tendencies were analyzed using three variables: partners' controlling behavior and alcohol consumption, and the women's attitude towards their partners. To measure partners' control, women were asked whether their present partners: a) were jealous if respondents talked with other men; b) accused them of unfaithfulness; c) did not permit them to meet female friends; d) tried to limit respondents' contact with family and e) insisted on knowing where they were. All these variables had binary responses $(0=$ no and $1=$ yes $)$.

Partner's alcohol consumption was measured by two questions: a) Does your partner drink alcohol? This was coded as binary outcome $(0=$ No, $1=$ Yes $)$. The second follow up question was asked to those who said yes to drinking alcohol: b) How often does (did) he get drunk: often, only sometimes, or never? The response categories were; $0=$ never, $1=$ often, $2=$ sometimes). We generated a new measure of alcohol consumption from the second question and included those who do not drink alcohol. The new variable had four categories $(0=$ does not drink, $1=$ drinks, but never gets drunk, $2=$ drinks and sometimes gets drunk and $3=$ drinks and often gets drunk). We also included women's attitude towards their partners - whether they were afraid of their partners - in this category of variables. Women were asked if they were afraid of their partners. This was categorized as $0=$ never, $1=$ sometimes and $2=$ most of the time.

Women's socio-demographic characteristics included women's age group, women's education level, region, place of residence, wealth index, parity or number of children ever born and current marital status (married or cohabiting). Witnessing of parental intimate partner violence was measured by whether the respondent reported ever witnessing her father beating her mother (with a binary outcome of $0=$ No, $1=$ Yes). The analysis also included age at first sex and duration of the union.

\section{Statistical analyses}

We used frequency distributions to describe the characteristics of the women. Cross-tabulations with Pearson's chi-squared $\left(\chi^{2}\right)$ tests were used to examine the associations between IPSV and women's empowerment (economic empowerment, attitudes justifying physical violence, and decision-making autonomy), partners' behaviors, and women's socio-demographic factors. The level of statistical significance using $\mathrm{p}$-values was set at $p<0.05$.

Finally, we conducted multivariable logistic regression analyses to examine the association between IPSV and the selected explanatory variables whose p-values were less than 0.05 during the chi-square tests. We presented the results in the form of Odds Ratios (OR) and their $95 \%$ confidence intervals. The level of statistical significance using $\mathrm{p}$-values was set at $p<0.05$. We estimated three models during the multivariable analysis. In the first step, IPSV was modeled with decision-making indicators and attitudes justifying wife beating. In the second model, we added partners' controlling behaviors and women's fear of their partners. In the final model, we adjusted for sociodemographic factors. We weighted all of the analyses to take into consideration the survey design, clustering and stratification [26]. 


\section{Results}

Distribution of respondents by socio-demographic characteristics and measures of empowerment

From Table 1, 41\% of the women were aged 25-34 years. There was nearly an even distribution of women by region, although more than a quarter (28\%) were from the central region. Most (84\%) of the women were rural residents. Most (70\%) engaged in sex before they were 18 years. More than half (55\%) were married and had been in a union for over 10 years (55\%). Half (50\%) of the women reported giving birth to between 1 and 4 children in their lifetime. More than half (60\%) had primary education and $41 \%$ were from the richer and richest wealth quintiles. Close to half (46\%) had witnessed their fathers beat their mothers during childhood.

Concerning measures of women's empowerment, just over half $(53 \%)$ of the women were engaged in agriculture, more than half (57\%) reported ownership of a house either alone or jointly. Participation in household decisionmaking among women in a union was as follows: how women's earnings were spent (44\%); women's own healthcare (59\%); large household purchases (56\%); visits to women's family (58\%); and how their partners' earnings were used (46\%).

The prevalence of attitudes justifying physical violence varied. Wife beating was justified if the woman: went out without telling her partner (41\%); neglected their children (48\%); argued with her partner $(30 \%)$; refused sex with her partner (24\%); or burnt food (15\%). Just over one in four (27\%) women in a union reported having experienced IPSV in the 12 months preceding the survey.

\section{The association between IPSV and women's socio-demographic characteristics and empowerment indicators}

Results of the cross tabulations in Table 1 show that region, age at first sex, women's level of education, and whether the woman's father beat her mother were significantly associated with IPSV. Among the measures of empowerment, IPSV was only significantly associated with decision-making regarding the partner's income, and with attitudes towards wife beating only if the woman neglected their children, argued with her partner, or burnt food. However, some of the key measures of economic empowerment, such as property ownership and decisionmaking concerning large purchases were not significantly associated with IPSV (see Table 1).

\section{Distribution of respondents by their' partners' background and behavioral factors}

Table 2 presents male partners' background characteristics, their behavior (controlling tendencies and alcohol consumption) and women's fear of their partners. Over half $(55 \%)$ of the partners were aged 35 years and above. Over a third (36\%) had secondary or higher education. Concerning partners' controlling behavior, over half of the women reported that their partners were jealous if they talked with men (56\%), and insisted on knowing where they were (55\%). Less than one third reported that their partners accused them of unfaithfulness, did not permit them to meet female friends, and limited their contact with family (32\%, $26 \%$ and $18 \%$ respectively). Four in ten (40\%) of the women had partners who got drunk and $46 \%$ of the women were afraid of their partners.

The association between IPSV among women in a union and partners' behaviors

In Table 2, all measures of male partners' controlling behaviors, alcohol consumption, and women's attitudes towards their partners were strongly associated with reporting IPSV. IPSV was higher among women whose partners were jealous when they talked to other men (35\%), accused them of unfaithfulness (41\%), denied them permission to meet female friends (42\%), limited contact with family (46\%), and insisted on knowing their whereabouts (33\%). IPSV was higher among women whose partners often got drunk (44\%) and among women who were often afraid of their partners (39\%). Partner's age and level of education were not significantly associated with IPSV.

\section{Multivariable results}

Table 3 shows the results of logistic regression of IPSV controlling for empowerment indicators and selected explanatory variables. In the first model, we adjusted for decision-making and attitudes justifying wife beating. Woman's participation in decision-making concerning the partner's income was the only significant predictor of IPSV. Women who participated in decision-making concerning their partners' incomes had reduced odds $(\mathrm{OR}=0.63$; 95\% CI: $0.47-0.86)$ of experiencing IPSV in comparison to those who did not.

In the second model, we added partners' behaviors and women's fear of their partners. Partners' behaviors and women's fear of their partner weakened women's participation in decision-making concerning their partners' income. Among partner's behaviors, significant predictors of IPSV were if the partner was jealous if the woman talked with other men, did not permit the respondent to meet female friends, tried to limit the woman's contact with family, and the frequency of the partner's excessive alcohol consumption. Whether the woman was afraid of her partner was also significantly associated with IPSV. The odds of reporting IPSV were higher among women whose partners were jealous if they talked to other men $(\mathrm{OR}=1.93 ; 95 \% \mathrm{CI}: 1.28-2.90)$, did not permit the respondent to meet female friends $(\mathrm{OR}=1.53$; 95\% CI: 1.03-2.27), and tried to limit her contact with 
Table 1 Percentage distribution of married women socio-demographics and experience of intimate partner sexual violence (IPSV) in Uganda (DHS 2011)

\begin{tabular}{llll}
\hline Variables & $\begin{array}{l}\text { \% of } \\
\text { women }\end{array}$ & Frequency & $\begin{array}{c}\% \text { r } \\
\text { IPS }\end{array}$ \\
\hline Age group & & & \\
$15-24$ & 29.7 & 388 & 24.6 \\
$25-34$ & 40.6 & 531 & 28.7 \\
$35+$ & 29.7 & 388 & 25.4 \\
Region & & & \\
Central & 28.0 & 366 & 24.9 \\
Eastern & 26.3 & 344 & 34.4 \\
Northern & 19.2 & 251 & 26.0 \\
Western & 26.4 & 346 & 20.7 \\
Residence & & & \\
Urban & 16.4 & 214 & 23.0 \\
Rural & 83.6 & 1093 & 27.2 \\
Age at first sex & & & \\
18+ & 29.9 & 391 & 20.8 \\
$<14$ & 22.8 & 298 & 29.2 \\
$15-17$ & 47.3 & 618 & 28.8 \\
\hline
\end{tabular}

Current marital status

Married

Cohabiting

$55.3 \quad 723$

24.4

$44.7 \quad 584$

29.1

Duration of union

in years

$\begin{array}{llll}0-4 & 24.1 & 315 & 22.3 \\ 5-9 & 20.8 & 272 & 27.5 \\ 10-14 & 18.7 & 244 & 27.6 \\ 15-19 & 15.3 & 199 & 26.3 \\ 20+ & 21.2 & 277 & 29.5\end{array}$

Parity

$\begin{array}{llll}0 & 6.7 & 87 & 19.7 \\ 1-4 & 50.0 & 653 & 25.3 \\ 5+ & 43.4 & 567 & 29.0\end{array}$

Women's education level

$\begin{array}{llll}\text { No education } & 17.0 & 222 & 24.1 \\ \text { Primary } & 60.1 & 785 & 29.9 \\ \text { Secondary } & 22.9 & 299 & 19.5 \\ \text { Wealth index } & & & \\ \text { Poorest } & 18.6 & 243 & 30.3 \\ \text { Poorer } & 19.9 & 260 & 29.3 \\ \text { Middle } & 20.1 & 262 & 28.1 \\ \text { Richer } & 19.5 & 255 & 26.9 \\ \text { Richest } & 21.9 & 287 & 19.0\end{array}$

0.459

0.006

0.038

0.119

0.537

0.297

0.017

0.105
Table 1 Percentage distribution of married women socio-demographics and experience of intimate partner sexual violence (IPSV) in Uganda (DHS 2011) (Continued)

Woman's father ever 0.004 beat her mother

$\begin{array}{llll}\text { No } & 43.0 & 562 & 22.1 \\ \text { Yes } & 45.9 & 600 & 31.7 \\ \text { Don't know } & 11.1 & 144 & 22.2\end{array}$

Women's occupation

Not working

$23.7 \quad 310 \quad 24.3$

$\begin{array}{llll}\text { Professional/technical/ } & 4.0 & 52 & 9.1\end{array}$

managerial

Agriculture

$53.4 \quad 698$

28.5

Sales

$18.9 \quad 247$

27.5

0.262 Woman owns house alone or jointly

No

$\begin{array}{lll}42.7 & 558 & 25.1\end{array}$

Yes

$\begin{array}{lll}57.3 & 749 & 27.6\end{array}$

Woman decides alone or jointly on:

Spending her income

0.406

No

$56.2 \quad 734$

25.4

$43.8 \quad 573$

27.9

Her own healthcare

0.506

No

$\begin{array}{lll}40.8 & 533 & 27.7\end{array}$

$59.2 \quad 774$

25.7

Large household purchases

No

Yes

$43.8 \quad 572$

27.9

$56.2 \quad 735$

25.4

Visits to family

0.177

No

$42.4 \quad 555$

28.9

Yes

$57.6 \quad 752$

24.8

What to do with

partner's income

$\begin{array}{lll}54.3 & 710 & 30.6\end{array}$

No

$45.7 \quad 597$

21.7

Beating justified if wife:

Goes out without telling husband

No

$\begin{array}{lll}59.1 & 772 & 25.6\end{array}$

Yes

$40.9 \quad 535$

27.8

Neglects the children

0.021

No

$52.3 \quad 683$

23.3

Yes

$47.7 \quad 624$

30.1

Argues with husband

0.014

Yes

$30.2 \quad 395$

32.1 
Table 1 Percentage distribution of married women socio-demographics and experience of intimate partner sexual violence (IPSV) in Uganda (DHS 2011) (Continued)

Refuses to have sex with husband

\begin{tabular}{lllll} 
No & 76.2 & 996 & 26.4 & \\
Yes & 23.8 & 311 & 27.0 & \\
Burns the food & & & & $\mathbf{0 . 0 4 6}$ \\
No & 85.0 & 1112 & 25.4 & \\
Yes & 15.0 & 195 & 33.1 & \\
Total & 100.0 & 1307 & 26.5 & \\
\hline
\end{tabular}

family $(\mathrm{OR}=1.82 ; 95 \% \mathrm{CI}: 1.16-2.83)$. Women whose partners often got drunk had increased odds $(\mathrm{OR}=$ 1.80; 95\% CI: 1.18-2.77) of reporting IPSV. Likewise, woman who were sometimes or often afraid of their partners were more likely to report IPSV $(\mathrm{OR}=1.82$; 95\% CI: 1.25-2.65 for women who were sometimes afraid, and $\mathrm{OR}=1.59 ; 95 \% \mathrm{CI}: 1.04-2.44$ for those who were often afraid).

In the final model, we adjusted for socio-demographic factors. While most of the partners' behaviors and women's attitude towards their partners retained their significance, women's empowerment and socio-demographic variables were not significant. The odds of reporting IPSV were higher among women whose partners were jealous if they talked with other men $(\mathrm{OR}=1.81 ; 95 \% \mathrm{CI}$ : 1.22-2.68), accused them of unfaithfulness $(\mathrm{OR}=1.50 ; 95 \% \mathrm{CI}$ : 1.03-2.19) and did not permit them to meet with their female friends $(\mathrm{OR}=1.63$; 95\% CI: 1.11-2.39). The odds of IPSV were also higher among women whose partners tried to limit their contact with family $(\mathrm{OR}=1.73 ; 95 \% \mathrm{CI}: 1.11-2.67)$ and often got drunk $(\mathrm{OR}=1.80 ; 95 \% \mathrm{CI}: 1.15-2.81)$. Women who were sometimes or often afraid of their partners had increased odds of reporting IPSV (OR = 1.78; 95\% CI: 1.21-2.60 and $\mathrm{OR}=1.58$; $95 \% \mathrm{CI}: 1.04-2.40$ respectively).

\section{Discussion}

The aim of this study was to examine the association between women's empowerment, partners' controlling behaviors and IPSV. The prevalence of IPSV among women in a union was high.

Male partners' controlling behaviors were the main predictors of IPSV among women in a union in Uganda. Being jealous if their partner talked with other men, accusing her of unfaithfulness, not permitting her to meet with female friends, and trying to limit her contact with family, were associated with IPSV. Other studies elsewhere have reported an association between male partners' controlling behaviors and IPSV $[12,13]$. In the case of IPSV, women's empowerment as measured by the UDHS $[8,9]$ and their socio-demographic characteristics
Table 2 Percentage distribution of married women by male partners' related factors, controlling behaviors and experience of IPSV in Uganda (DHS 2011)

\begin{tabular}{llll}
\hline Variables & $\begin{array}{l}\text { \% of } \\
\text { women }\end{array}$ & Frequency & $\begin{array}{l}\% \text { r } \\
\text { IPSV }\end{array}$ \\
\hline Partners' age group & & & \\
$15-24$ & 9.9 & 130 & 22.2 \\
$25-34$ & 35 & 458 & 25.3 \\
$35-44$ & 31.8 & 416 & 30.0 \\
$45+$ & 23.2 & 303 & 25.4 \\
Partner's education & & & \\
level & & & \\
No education & 10.1 & 132 & 25.6 \\
Primary & 54 & 706 & 29.9 \\
Secondary & 27.5 & 360 & 22.6 \\
Higher & 8.4 & 109 & 18.8
\end{tabular}

Husband/partner:

Jealous if woman talks with men

No

Yes

Accuses her of unfaithfulness

No

Yes

Does not permit her

to meet female friends No

Yes

Limits her contact with family

No

Yes

Insists on knowing where she is

\begin{tabular}{lllll} 
No & 45.2 & 591 & 18.4 & \\
Yes & 54.8 & 716 & 33.2 & $\mathbf{0 . 0 0 0}$ \\
$\begin{array}{l}\text { Partner drinks alcohol } \\
\text { No }\end{array}$ & 55.0 & 719 & 25.4 & \\
$\begin{array}{l}\text { Yes, but never gets } \\
\text { drunk }\end{array}$ & 4.8 & 63 & 8.3 & \\
$\begin{array}{l}\text { Yes, sometimes gets } \\
\text { drunk }\end{array}$ & 25.0 & 326 & 21.8 & \\
$\begin{array}{l}\text { Yes, often gets drunk } \\
\text { Woman afraid of }\end{array}$ & 15.2 & 199 & 44.1 & $\mathbf{0 . 0 0 0}$ \\
partner & & & & \\
Never & 54.4 & 711 & 18.2 & \\
$\begin{array}{l}\text { Sometimes } \\
\text { Often }\end{array}$ & 27.1 & 354 & 35.1 & \\
Total & 18.5 & 242 & 38.5 & \\
\hline & 100 & 1307 & 26.5 & \\
\hline
\end{tabular}

0.000

0.000

$\begin{array}{lll}81.5 & 1066 & 21.9 \\ 18.5 & 241 & 46.8\end{array}$

0.000

$\begin{array}{lll}73.8 & 965 & 21.1 \\ 26.2 & 342 & 41.8\end{array}$

41.8

1.9

46.8

.000 
Table 3 Results of logistic regression of IPSV and empowerment indicators controlling for women's socio-demographic factors and male partners' controlling behaviors in Uganda (DHS 2011)

\begin{tabular}{|c|c|c|c|c|c|c|}
\hline \multicolumn{7}{|c|}{ Experienced intimate partner sexual violence (IPSV) in the last 12 months preceding the survey } \\
\hline \multirow[b]{2}{*}{ Variables } & \multicolumn{2}{|c|}{ Model (1) } & \multicolumn{2}{|c|}{ Model (2) } & \multicolumn{2}{|c|}{ Model (3) } \\
\hline & ORs & $95 \% \mathrm{Cl}$ & ORs & $95 \% \mathrm{Cl}$ & ORs & $95 \% \mathrm{Cl}$ \\
\hline Woman decides on partner's income alone or jointly $(\mathrm{RC}=\mathrm{No})$ & $0.633^{* *}$ & {$[0.47-0.86]$} & 0.743 & [0.53-1.04] & 0.774 & {$[0.55-1.08]$} \\
\hline \multicolumn{7}{|l|}{ Beating justified if wife: } \\
\hline Neglects the children $(\mathrm{RC}=\mathrm{No})$ & 1.224 & {$[0.87-1.71]$} & 1.259 & [0.88-1.79] & 1.260 & {$[0.88-1.80]$} \\
\hline Argues with husband $(\mathrm{RC}=\mathrm{No})$ & 1.247 & {$[0.86-1.80]$} & 1.016 & {$[0.69-1.50]$} & 0.945 & {$[0.63-1.41]$} \\
\hline Burns the food $(\mathrm{RC}=\mathrm{No})$ & 1.195 & {$[0.79-1.81]$} & 1.094 & {$[0.70-1.71]$} & 1.051 & {$[0.67-1.65]$} \\
\hline \multicolumn{7}{|l|}{ Husband/partner: } \\
\hline Jealous if woman talks with other men $(\mathrm{RC}=\mathrm{No})$ & & & $1.930^{* *}$ & {$[1.28-2.90]$} & $1.808^{* *}$ & {$[1.22-2.68]$} \\
\hline Accuses respondent of unfaithfulness $(\mathrm{RC}=\mathrm{No})$ & & & 1.455 & {$[1.00-2.12]$} & $1.501^{*}$ & {$[1.03-2.19]$} \\
\hline Does not permit respondent to meet female friends $(\mathrm{RC}=\mathrm{No})$ & & & $1.530^{*}$ & {$[1.03-2.27]$} & $1.630^{*}$ & [1.11-2.39] \\
\hline Tries to limit respondent's contact with family $(\mathrm{RC}=\mathrm{No})$ & & & $1.815^{* *}$ & [1.16-2.83] & $1.725^{*}$ & {$[1.11-2.67]$} \\
\hline Insists on knowing where respondent is $(\mathrm{RC}=\mathrm{No})$ & & & 0.968 & {$[0.66-1.42]$} & 0.940 & {$[0.64-1.37]$} \\
\hline \multicolumn{7}{|l|}{ Partner drinks alcohol $(\mathrm{RC}=\mathrm{No})$} \\
\hline Yes, but never gets drunk & & & $0.294^{* *}$ & {$[0.13-0.66]$} & $0.313^{* *}$ & {$[0.14-0.71]$} \\
\hline Yes, sometimes gets drunk & & & 0.688 & {$[0.46-1.04]$} & 0.717 & {$[0.47-1.10]$} \\
\hline Yes, often gets drunk & & & $1.803^{* *}$ & {$[1.18-2.77]$} & $1.800^{* *}$ & [1.15-2.81] \\
\hline \multicolumn{7}{|l|}{ Woman afraid of partner $(\mathrm{RC}=$ Never $)$} \\
\hline Sometimes & & & $1.819^{* *}$ & {$[1.25-2.65]$} & $1.777^{* *}$ & {$[1.21-2.60]$} \\
\hline Often & & & $1.593^{*}$ & {$[1.04-2.44]$} & $1.578^{*}$ & {$[1.04-2.40]$} \\
\hline \multicolumn{7}{|l|}{ Region $(\mathrm{RC}=$ Central) } \\
\hline Eastern & & & & & 1.051 & {$[0.65-1.69]$} \\
\hline Northern & & & & & 0.985 & {$[0.62-1.57]$} \\
\hline Western & & & & & 0.754 & {$[0.46-1.24]$} \\
\hline \multicolumn{7}{|l|}{ Women's education level (RC = None) } \\
\hline Primary & & & & & 1.269 & {$[0.82-1.96]$} \\
\hline Secondary & & & & & 0.882 & {$[0.46-1.68]$} \\
\hline \multicolumn{7}{|l|}{ Woman's father ever beat her mother $(\mathrm{RC}=\mathrm{No})$} \\
\hline Yes & & & & & 1.347 & {$[0.96-1.88]$} \\
\hline Don't know & & & & & 0.964 & {$[0.55-1.69]$} \\
\hline \multicolumn{7}{|l|}{ Age at first sex ( $R C=18+$ years $)$} \\
\hline$<14$ years & & & & & 0.949 & {$[0.59-1.54]$} \\
\hline $15-17$ years & & & & & 1.159 & {$[0.78-1.73]$} \\
\hline Weighted sample & 1307 & & 1307 & & 1307 & \\
\hline
\end{tabular}

ORs = Odds Ratios; $\mathrm{Cl}=$ Confidence Interval; $\mathrm{RC}=$ Reference Category; ${ }^{*} \mathrm{p}<0.05-{ }^{* *} \mathrm{p}<0.01-{ }^{* * *} \mathrm{p}<0.001$.

were not significant predictors of IPSV after adjusting for partners' controlling behaviors. It is apparent that IPSV would occur irrespective of women's empowerment or socio-demographic background, if their partners exhibit excessive controlling tendencies and alcohol consumption.

Women's fear of their partners (which is most likely a result of partners' abusive behaviors) was associated with IPSV. Women who were afraid of their partners were less likely to say no to the sexual advances of their partners due to the threat of physical violence [20]. As noted earlier, their fear could also be a result of IPSV [19]. Excessive alcohol consumption (often getting drunk) remains a significant predictor of both intimate partner sexual and physical violence [20]. This finding has been reported in South Africa [12] and Rwanda [17].

In this paper, some of the predictors of IPSV varied from those of IPPV in other studies [12,13,18,20]. Significant predictors of IPPV, namely parity, wealth status, 
woman's occupation, experience of parental violence, and the partner insisting on knowing his wife's whereabouts did not have a significant relationship with IPSV. On the other hand, the significant predictors of IPSV in this paper the partner being jealous if the woman talked with other men, and the partner trying to limit the woman's contact with her family - did not predict the occurrence of IPPV in another Ugandan study [20]. Our findings confirm that there are variations between predictors of IPSV and IPPV. The common predictors of IPPV and IPSV were accusing wives of unfaithfulness, not permitting women to meet female friends, getting drunk, and women's fear of their partners [20].

While witnessing parental physical violence was a significant predictor of IPPV $[18,20]$, it did not predict the occurrence of IPSV. Although it is possible that witnessing parental IPSV could result in IPSV, the UDHS did not address this question (perhaps owing to its sensitivity).

None of the socio-demographic factors considered (age of the woman, age at first sex, type of union, level of education and region), were significant predictors of IPSV among women in a union Uganda. This is contrary to findings elsewhere in Africa $[11,13,17]$. While the duration of the union and women's control over their incomes were significant predictors of IPSV in Rwanda [17], this was not the case in Uganda. In addition, neither women's empowerment (including their participation in household decisionmaking, their attitudes towards wife beating, their control over their incomes, and their occupation) nor their household wealth status, were significant predictors of IPSV in the context of their partners' dysfunctional behaviors.

\section{Conclusions}

In Uganda, women's socio-economic and demographic backgrounds and empowerment had no mitigating effect on IPSV in the face of their partners' dysfunctional behaviours. Interventions addressing IPSV should target men, placing more emphasis on addressing the root causes of their controlling behavioral tendencies, and the prevention of problem drinking.

\section{Competing interests}

The authors declare that they have no competing interests.

\section{Authors' contributions}

SOW and BK conceptualized and designed the study. BK, AK, and PN wrote the background section. BK and SOW wrote results and discussion sections. SOW wrote the methods section and analyzed data. BK, AK, SOW revised the discussion section. All authors proofread and reviewed the manuscript.

\section{Authors' information}

SOW is an Assistant Lecturer at the Department of Population Studies and a PhD student at Makerere University. His research interests are in access to healthcare for older persons and sexual and gender-based violence in Uganda. He holds a Master of Science in Population and Reproductive Health and a Bachelor of Science in Population Studies. BK is a senior lecturer and a former chair of the Department of Population Studies, School of Statistics and Planning, College of Business and
Management, Makerere University. BK holds a PhD in Sociology, University of Vienna, Masters in Development Studies (Women and Development), Institute of Social Studies, at the Hague. Her research interests are in health systems, sexual and reproductive health.

PN is an Assistant Lecturer and acting chair of the Department of Population Studies, Makerere University. She holds a Master of Public Health from Lund University, Sweden and a Master of Science in Population and Reproductive Health (Makerere University) and a Bachelor of Science in Population Studies. Her research interests are in maternal health and Sexual and Gender-Based Violence.

AK is an Assistant Lecturer at the Department of Population Studies, Makerere University. She is doing a PhD research on stalling fertility in Uganda. She holds a Master of Arts in Demography (Makerere University) and a Bachelor of Arts in Education. Her research interests lie in family planning, maternal and child health, fertility and gender-based studies.

\section{Acknowledgements}

We thank Measure DHS for granting us permission to use the UDHS data. We express our gratitude to Mr. Ben Damian Pedley and Mr. Andrew Jamali, of the University of Southampton, for their editorial support.

Received: 6 September 2014 Accepted: 17 February 2015

Published online: 04 March 2015

\section{References}

1. Garcia-Moreno C, Jansen HAFM, Ellsberg M, Heise L, Watts CH. Prevalence of intimate partner violence: findings from the WHO multi-country study on women's health and domestic violence. Lancet. 2006;368(9543):1260-9.

2. Koenig MA, Stephenson R, Ahmed S, Jejeebhoy SJ, Campbell J: Individual and contextual determinants of domestic violence in North India. J Inf 2006, 96(1).

3. Diop-Sidibé N, Campbell JC, Becker S. Domestic violence against women in Egypt-wife beating and health outcomes. Soc Sci Med. 2006;62(5):1260-77.

4. Polis CB, Lutalo T, Wawer M, Serwadda D, Kigozi G, Nalugoda F, et al. Coerced sexual debut and lifetime abortion attempts among women in Rakai, Uganda. Int J Gynecol Obstet. 2009;104(2):105-9.

5. Silverman JG, Decker MR, Saggurti N, Balaiah D, Raj A. Intimate partner violence and HIV infection among married Indian women. JAMA. 2008;300(6):703-10.

6. Osinde MO, Kaye DK, Kakaire O. Intimate partner violence among women with HIV infection in rural Uganda: critical implications for policy and practice. BMC Womens Health. 2011;11:50.

7. Andersson N, Omer K, Caldwell D, Dambam M, Maikudi A, Effiong B, et al. Male responsibility and maternal morbidity: a cross-sectional study in two Nigerian states. BMC Health Serv Res. 2011;11 Suppl 2:S7.

8. UBOS, ICF International. Uganda Demographic and Health Survey 2011. Kampala, Uganda: UBOS and Calverton, Maryland: ICF International Inc; 2012.

9. UBOS, Macro International. Uganda Demographic and Health Survey 2006. Calverton, Maryland, USA \& UBOS, Kampala Uganda: Uganda Bureau of Statistics \& Macro International Inc; 2007.

10. Abrahams $N$, Jewkes R, Hoffman M, Laubsher R. Sexual violence against intimate partners in Cape Town: prevalence and risk factors reported by men. Bull World Health Organ. 2004;82(5):330-7.

11. Wagman JA, Namatovu F, Nalugoda F, Kiwanuka D, Nakigozi G, Gray R, et al. A public health approach to intimate partner violence prevention in Uganda: the SHARE project. Violence Against Women. 2012;18(12):1390-412.

12. Jewkes R, Levin J, Penn-Kekana L. Risk factors for domestic violence: findings from a South African cross-sectional study. Soc Sci Med. 2002;55(9):1603-17.

13. Seedat M, Van Niekerk A, Jewkes R, Suffla S, Ratele K. Violence and injuries in South Africa: prioritising an agenda for prevention. Lancet. 2009;374(9694):1011-22.

14. Karamagi C, Tumwine J, Tylleskar T, Heggenhougen K. Intimate partner violence against women in eastern Uganda: implications for HIV prevention. BMC Public Health. 2006;6(1):284.

15. Wandera SO, Ntozi JPM, Kwagala B. Spousal sexual violence, sexual behavior and sexually transmitted infections among ever-married women in Uganda. Afr Popul Stud. 2010;24(1\&2):70-87.

16. Castro R, Casique I, Brindis CD. Empowerment and physical violence throughout women's reproductive life in Mexico. Violence Against Women. 2008;14(6):655-77. 
17. Ntaganira J, Muula A, Masaisa F, Dusabeyezu F, Siziya S, Rudatsikira E. Intimate partner violence among pregnant women in Rwanda. BMC Womens Health. 2008;8(1):17.

18. Abeya Sileshi G, Afework Mesganaw F, Yalew Alemayehu W. Intimate partner violence against women in western Ethiopia: prevalence, patterns, and associated factors. BMC Public Health. 2011;11(1):913.

19. Campbell JC. Health consequences of intimate partner violence. Lancet. 2002;359(9314):1331-6.

20. Kwagala B, Wandera S, Ndugga P, Kabagenyi A. Empowerment, partner's behaviours and intimate partner physical violence among married women in Uganda. BMC Public Health. 2013;13(1):1112.

21. Tumwesigye N, Kyomuhendo G, Greenfield T, Wanyenze R. Problem drinking and physical intimate partner violence against women: evidence from a national survey in Uganda. BMC Public Health. 2012;12(1):399.

22. Speizer IS. Intimate partner violence attitudes and experience among women and men in Uganda. J Interpers Violence. 2010;25(7):1224-41.

23. Koenig MA, Lutalo T, Zhao F, Nalugoda F, Kiwanuka N, Wabwire-Mangen F, et al. Coercive sex in rural Uganda: prevalence and associated risk factors. Soc Sci Med. 2004;58(4):787-98.

24. Measure DHS. Demographic and Health Surveys [http://dhsprogram.com/ data/dataset/Uganda_Standard-DHS_2011.cfm?flag=0]

25. UBOS. The 2002 Uganda Population and Housing Census. In: Main Report. Kampala, Uganda: Uganda Bureau of Statistics; 2002.

26. StatCorp. Stata: Release 13. Statistical Software. College Station, TX: StataCorp LP; 2014.

27. Straus MA, Hamby SL, Boney-McCoy S, Sugarman DB. The revised Conflict Tactics Scales (CTS2) development and preliminary psychometric data. J Fam Issues. 1996;17(3):283-316.

28. WHO. Putting women first: ethical and safety recommendations for research on domestic violence against women. Geneva, Switzerland: World Health Organization; 2001.

29. Antai D. Controlling behavior, power relations within intimate relationships and intimate partner physical and sexual violence against women in Nigeria. BMC Public Health. 2011;11:511.

30. Lee-Rife SM. Women's empowerment and reproductive life experiences over the lifecourse. Soc Sci Med. 2010;71:634-42.

\section{Submit your next manuscript to BioMed Central and take full advantage of:}

- Convenient online submission

- Thorough peer review

- No space constraints or color figure charges

- Immediate publication on acceptance

- Inclusion in PubMed, CAS, Scopus and Google Scholar

- Research which is freely available for redistribution 